\title{
Cell-to-Cell Movement of the 25K Protein of Potato virus $X$ Is Regulated by Three Other Viral Proteins
}

\author{
Yang Yang, ${ }^{1}$ Biao Ding, ${ }^{2}$ David C. Baulcombe, ${ }^{3}$ and Jeanmarie Verchot ${ }^{1}$ \\ ${ }^{1}$ Department of Entomology and Plant Pathology, Oklahoma State University, Stillwater 74078, U.S.A.; \\ ${ }^{2}$ Botany Department, Oklahoma State University, Stillwater 74075, U.S.A.; ${ }^{3}$ Sainsbury Laboratory, \\ Norwich Research Park, Colney NR4 7UH, U.K. \\ Accepted 3 March 2000.
}

\begin{abstract}
The $25 \mathrm{~K}, 12 \mathrm{~K}$, and $8 \mathrm{~K}$ proteins and coat protein $(\mathrm{CP})$ of Potato virus $X(\mathrm{PVX})$ are required for virus cell-to-cell movement. In this study, experiments were conducted to determine whether the PVX 25K protein moves cell to cell and to explore potential interactions between the PVX 25K, 12K, and $8 \mathrm{~K}$ proteins and CP. The PVX $25 \mathrm{~K}$ gene was fused to the green fluorescent protein (GFP) gene and inserted into plasmids adjacent to the cauliflower mosaic virus 35S promoter. These plasmids were introduced by biolistic bombardment to transgenic tobacco expressing the PVX 12K, 8K, and CP genes. The GFP:25K fused proteins moved cell to cell on nontransgenic tobacco and tobacco expressing either the $12 \mathrm{~K}$ or $8 \mathrm{~K}$ proteins. However, the GFP:25K proteins did not move on transgenic tobacco expressing the combined $12 \mathrm{~K} / 8 \mathrm{~K}$ genes or the $\mathrm{CP}$ gene. Thus, movement of the PVX $25 \mathrm{~K}$ protein through plasmodesmata may be regulated by interactions with other PVX proteins.
\end{abstract}

Additional keywords: potexvirus, triple gene block proteins, viral movement protein.

Potexviruses contain a block of three partially overlapping reading frames termed the "triple gene block" (TGB) that encode proteins required for virus cell-to-cell movement (Huisman et al. 1988; Koonin and Dolja 1993). In the case of Potato virus $X$ (PVX), these three proteins are named, in accordance with their molecular mass, $25 \mathrm{~K}, 12 \mathrm{~K}$, and $8 \mathrm{~K}$ proteins (Huisman et al. 1988). It is likely that these three proteins interact with each other to facilitate viral intercellular transport, but the nature of these interactions remains poorly understood. Studies of the $25 \mathrm{~K}$ and $26 \mathrm{~K}$ proteins of the potexviruses PVX, White clover mosaic virus (WCIMV), and Foxtail mosaic virus have revealed that these proteins can bind RNA, increase the size exclusion limit of plasmodesmata, and move from cell to cell (Rouleau et al. 1994; Angell et al. 1996; Lough et al. 1998; Kalinina et al. 1998). Specific functions of the PVX $12 \mathrm{~K}$ and $8 \mathrm{~K}$ proteins are still obscure although they are suggested to have membrane-binding activities (Skryabin et al. 1988). The PVX coat protein (CP) is also

Corresponding author: Jeanmarie Verchot; Telephone: 1-405-744-7895; Fax: 1-405-744-6039; E-mail: verchot@okstate.edu required for viral cell-to-cell movement (Chapman et al. 1992; Forster et al. 1992; Baulcombe et al. 1995). The CP accumulates in plasmodesmata in infected cells but does not gate plasmodesmata (Oparka et al. 1996). It has been postulated for PVX and WCIMV that either virions or a complex containing the $25 \mathrm{~K}$ (26K of WCIMV) protein, $\mathrm{CP}$, and viral RNA are trafficking through plasmodesmata (Oparka et al. 1996; Santa Cruz et al. 1998; Lough et al. 1998), although such a complex has not been identified in vivo. Based on these limited studies, it is assumed that the PVX $25 \mathrm{~K}$ protein and CP are central to the viral movement process by providing most of the activities required for intercellular RNA trafficking. The $12 \mathrm{~K}$ and $8 \mathrm{~K}$ proteins would therefore provide activities accessory to the $25 \mathrm{~K}$ proteins. We suggest that there are two alternative roles for the $12 \mathrm{~K}$ and $8 \mathrm{~K}$ proteins. These proteins, functioning as membrane anchors, may play a more direct role by regulating viral RNA trafficking potentiated by $25 \mathrm{~K}$ proteins, or they may promote formation of a ribonucleoprotein trafficking complex early in the movement process. Alternatively, they may restrict $25 \mathrm{~K}$ protein plasmodesmatal gating activities late in infection as a means to restore normal intercellular communication.

In two previous studies, DNA constructs containing the green fluorescent protein (GFP) gene fused to the $3^{\prime}$ end of the PVX $25 \mathrm{~K}$ gene under the control of the $35 \mathrm{~S}$ promoter of $\mathrm{Cau}$ liflower mosaic virus (CaMV) were bombarded onto tobacco or potato leaves (Malcuit et al. 1999; Morozov et al. 1999). The resulting 25K:GFP fusion products were expressed in single cells and did not move cell to cell. In one study (Morozov et al. 1999) the 25K:GFP fusion proteins could complement cell-to-cell movement of $25 \mathrm{~K}$-deficient PVX viruses. These data suggested that cell-to-cell movement of the $25 \mathrm{~K}$ protein may not be essential for viral cell-to-cell movement. To investigate the cell-to-cell movement of the PVX $25 \mathrm{~K}$ protein we used biolistic bombardment to introduce similar constructs, containing the GFP gene fused to the $5^{\prime}$ or $3^{\prime}$ end of the $25 \mathrm{~K}$ gene, into tobacco leaves. The GFP:25K proteins did move cell to cell and complemented viral cell-tocell movement defects. In addition, these constructs were introduced by bombardment into transgenic tobacco expressing the $12 \mathrm{~K}, 8 \mathrm{~K}$, combined $12 \mathrm{~K} / 8 \mathrm{~K}$, or $\mathrm{CP}$ genes. These same transgenic tobacco lines were used in previous studies and the transgenic proteins were able to complement movementdefective PVX viruses (Verchot et al. 1998; Spillane et al. 
1997). On transgenic tobacco expressing the $12 \mathrm{~K} / 8 \mathrm{~K}$ genes together or the CP gene, GFP:25K proteins did not move cell to cell.

\section{RESULTS}

Fusion of GFP to the N terminus of the PVX 25K protein retained function of the $25 \mathrm{~K}$ protein in viral cell-to-cell movement.

The GFP:25K fused genes were expressed directly from the genome of 25K-deficient PVX. The plasmids pPVX204 and pPVX204. $25 \mathrm{~K}$ contain cDNA copies of the PVX genome (Baulcombe et al. 1995) fused to the CaMV 35S promoter. Both plasmids contain the GFP gene fused to a duplicated CP subgenomic (sg) RNA promoter inserted into the viral genome. pPVX204. $225 \mathrm{~K}$ contains a mutation deleting 357 nucleotides of the $25 \mathrm{~K}$ gene that inhibits viral cell-to-cell movement (Verchot et al. 1998). In pPVX204.GFP25K, the GFP gene in pPVX204. $25 \mathrm{~K}$ was replaced with the GFP:25K fused genes (Fig. 1A). To determine if the GFP:25K fused genes could restore infectivity to the 25K-deficient PVX virus, these three plasmids were delivered by biolistic bombardment to detached tobacco leaves. Viral cell-to-cell movement was monitored for 5 days by epifluorescence microscopy to detect GFP activity. Expanding infection foci were observed on leaves bombarded with the pPVX204 and
pPVX204.GFP25K plasmids but not on leaves bombarded with pPVX204. $25 \mathrm{~K}$ plasmids (Fig, 1B, C). These data indicate that the GFP:25K fused genes were able to restore viral cell-to-cell movement to $25 \mathrm{~K}$-deficient PVX viruses.

\section{Cell-to-cell movement of GFP:25K fusion proteins was inhibited in transgenic tobacco expressing both $12 \mathrm{~K}$ and $8 \mathrm{~K}$ genes or the $\mathrm{CP}$ gene.}

To directly determine whether the $25 \mathrm{~K}$ protein moves cell to cell, three different DNA constructs were prepared. Plasmids p25K:GFP and pGFP:25K contain the GFP gene fused to the $3^{\prime}$ and $5^{\prime}$ ends of the PVX $25 \mathrm{~K}$ gene, respectively. Plasmid pGFP contains only the GFP gene (Fig. 2). Expression of all genes is driven by the CaMV $35 \mathrm{~S}$ promoter. These plasmids were delivered to single epidermal cells of tobacco leaves by biolistic bombardment, and epifluorescence microscopy was used to study cell-to-cell movement of GFP, 25K:GFP, and GFP:25K proteins. These plasmids were also bombarded onto transgenic tobacco leaves expressing the PVX $12 \mathrm{~K}, 8 \mathrm{~K}$, both $12 \mathrm{~K}$ and $8 \mathrm{~K}$, or $\mathrm{CP}$ genes to determine if these three viral proteins affect movement of the $25 \mathrm{~K}$ protein. In addition, the pattern of protein accumulation was monitored to determine if there are differences in how the $25 \mathrm{~K}$ :GFP and GFP:25K proteins accumulate.

Transgenic tobacco line TGB100 expresses the PVX 25K gene, line TGB200 expresses the 12K gene, line TGB300 ex-

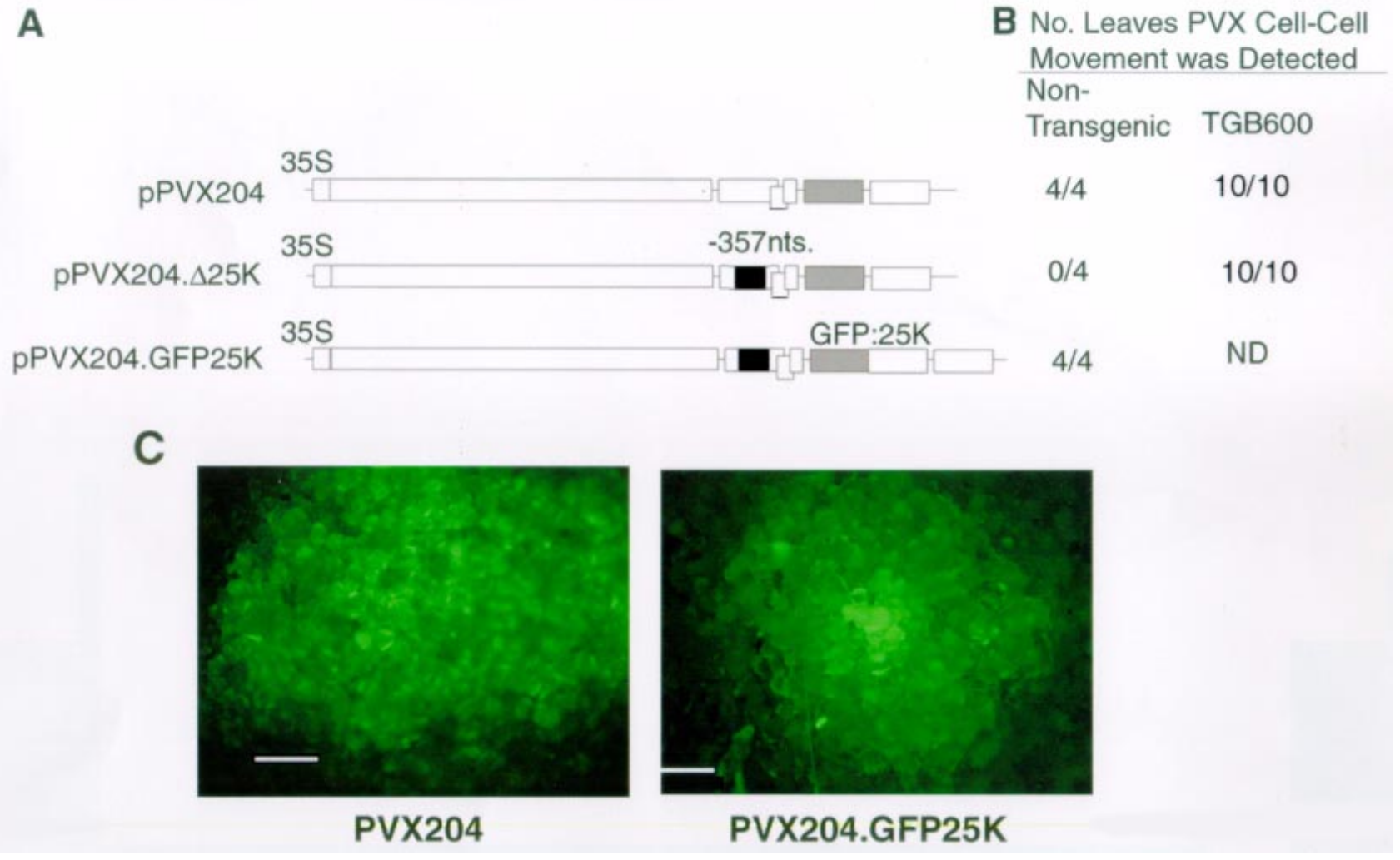

Fig 1. A, Schematic representation of plasmids containing cDNA copies of the Potato virus $X$ (PVX) genome (open boxes) fused to the $35 \mathrm{~S}$ promoter of Cauliflower mosaic virus (CaMV). Gray boxes indicate green fluorescent protein (GFP) genes inserted into the PVX genome next to a duplicated coat protein (CP) subgenomic (sg) RNA promoter. Deletion of 357 nucleotides in the $25 \mathrm{~K}$ gene is indicated in the plasmid pPVX204. $25 \mathrm{~K}$ and pPVX204.GFP25K by a black box. B, Nontransgenic and TGB600 transgenic tobacco expressing the PVX $12 \mathrm{~K}$ and 8K genes were inoculated with transcripts or DNAs and GFP fluorescence was used to monitor viral cell-to-cell movement. Expansion of infection foci was monitored for 5 to 10 days after inoculations. Numbers of leaves in which expanding infection foci were observed per total number of inoculated leaves are indicated. ND = not determined. C, Examples of infection sites observed at 5 days post bombardment on nontransgenic tobacco leaves with pPVX204 and pPVX204.GFP25K. 
presses the $8 \mathrm{~K}$ gene, line TGB600 expresses the $12 \mathrm{~K}$ and $8 \mathrm{~K}$ genes, and line $\mathrm{CP}$ expresses the $\mathrm{CP}$ gene (Fig. 3). The TGB600 line contains coding sequence for a bicistronic mRNA that resembles the bicistronic PVX sgRNA2. Previous studies demonstrated that viral proteins produced in these transgenic tobacco lines provide in trans complementation of defects in cell-to-cell movement of mutant PVX viruses
(Verchot et al. 1998; Spillane et al. 1997). Thus, we reasoned that in planta interactions between the viral proteins produced from the transgenic plants and the $25 \mathrm{~K}$ protein produced from plasmid bombardment would resemble functional interactions occurring during virus infection.

Plasmids were bombarded to sink and source tobacco leaves of the nontransgenic and transgenic tobacco leaves.

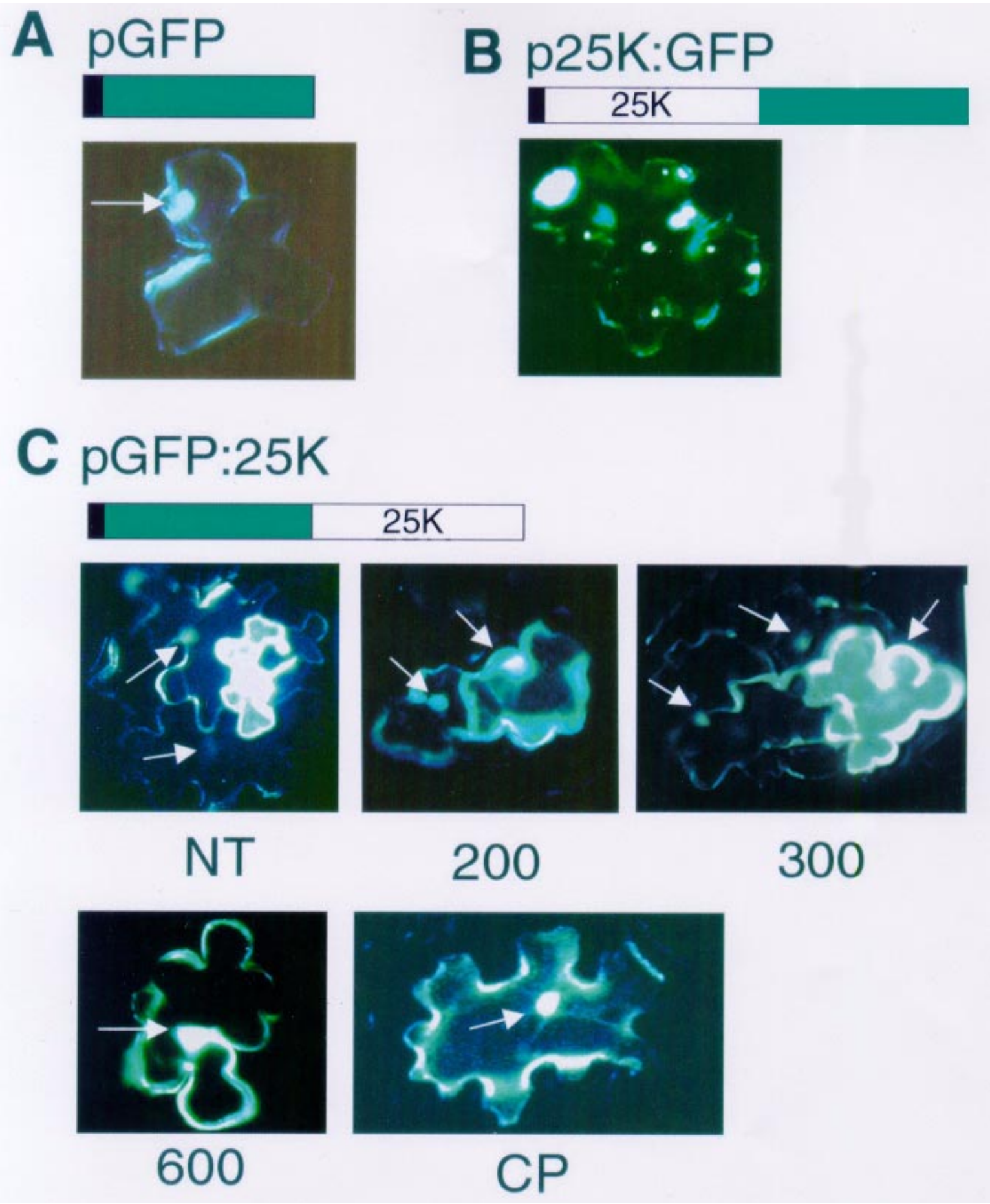

Fig. 2. Images of tobacco cells bombarded with pGFP, p25K:GFP, and pGFP:25K plasmids observed by fluorescence microscopy. Transgenic and nontransgenic cells are identified below images. A and B, Nontransgenic tobacco cells at 1 day post bombardment (dpb) with pGFP and p25KGFP plasmids. Images were taken with a $\times 40$ and a $\times 60$ objective lens, respectively. C, Images of nontransgenic $(\times 20$ objective lens $)$ and TGB200 ( $\times 40)$, TGB300 $(\times 40)$, TGB600 $(\times 60)$, and coat protein $(\mathrm{CP} ; \times 60)$ transgenic tobacco cells $1 \mathrm{dpb}$ with pGFP:25K. Arrows indicate nucleus in each cell. 
The physiological status of these leaves was determined by carboxyfluorescein (CF) translocation studies (Oparka et al. 1994; Roberts et al. 1997). Briefly, a young leaf that imported and unloaded CF was determined to be a sink and a fully expanded leaf that was unable to import CF was a source (data not shown). Between four and 14 nontransgenic or transgenic leaves were bombarded with each plasmid. Approximately $50 \%$ of the leaves bombarded with each plasmid were identified as sink leaves. There was little difference in the pattern of

\section{TGB100 $25 \mathrm{~K}$ TGB200 12K TGB300 $8 \mathrm{~K}$ TGB600 $12 \mathrm{~K}[\mathrm{~K}$

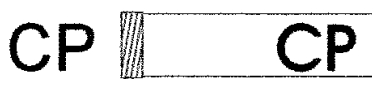

Fig. 3. Schematic representation of transgenes present in transgenic plants. The 35S promoter of Cauliflower mosaic virus (hatched boxes) is fused to the open reading frames of Potato virux $X$ (open boxes).

Table 1. Cell-to-cell movement of green fluorescent protein (GFP) and 25K:GFP, GFP:25K and 3a:GFP proteins

\begin{tabular}{|c|c|c|c|c|}
\hline \multirow[b]{2}{*}{ Plants } & \multicolumn{4}{|c|}{$\begin{array}{c}\text { Proportion of sites containing GFP activity } \\
\text { in multiple cells }{ }^{\mathbf{a}}\end{array}$} \\
\hline & GFP $^{\mathbf{b}}$ & $25 \mathrm{~K}: \mathrm{GFP}^{\mathrm{b}}$ & GFP:25K ${ }^{b}$ & 3a:GFP \\
\hline \multicolumn{5}{|c|}{ Nontransgenic } \\
\hline $1 \mathrm{dpb}$ & $0(0 / 142)$ & $0(0 / 120)$ & $34(10 / 29)$ & $20(21 / 104)$ \\
\hline $3 \mathrm{dpb}$ & $0(0 / 28)$ & $0(0 / 40)$ & $37(4 / 11)$ & ND \\
\hline \multicolumn{5}{|l|}{ TGB100 } \\
\hline $1 \mathrm{dpb}$ & $3(3 / 104)$ & $\mathrm{ND}^{\mathrm{c}}$ & ND & ND \\
\hline $3 \mathrm{dpb}$ & $4(1 / 23)$ & ND & ND & ND \\
\hline \multicolumn{5}{|l|}{ TGB200 } \\
\hline $1 \mathrm{dpb}$ & $0(0 / 117)$ & $0(0 / 79)$ & $50(16 / 32)$ & ND \\
\hline $3 \mathrm{dpb}$ & $0(0 / 23)$ & $0(0 / 10)$ & $53(8 / 15)$ & ND \\
\hline \multicolumn{5}{|l|}{ TGB300 } \\
\hline $1 \mathrm{dpb}$ & $0(0 / 100)$ & $4(2 / 81)$ & $50(21 / 42)$ & ND \\
\hline $3 \mathrm{dpb}$ & $0(0 / 27)$ & $0(0 / 10)$ & $61(13 / 21)$ & ND \\
\hline \multicolumn{5}{|l|}{ TGB600 } \\
\hline $1 \mathrm{dpb}$ & $0 \%(0 / 138)$ & $5 \%(9 / 174)$ & $6 \%(3 / 52)^{\mathrm{d}}$ & $17(22 / 131)$ \\
\hline $3 \mathrm{dpb}$ & $0(0 / 33)$ & $0(0 / 30)$ & $4(1 / 25)$ & ND \\
\hline \multicolumn{5}{|l|}{$\mathrm{CP}$} \\
\hline $1 \mathrm{dpb}$ & $0(0 / 60)$ & $0(0 / 26)$ & $5(2 / 41)^{d}$ & $18(20 / 112)$ \\
\hline $3 \mathrm{dpb}$ & $0(0 / 18)$ & $0(0 / 10)$ & $5(1 / 19)$ & ND \\
\hline
\end{tabular}

${ }^{a}$ Percentage of fluorescent cell clusters is indicated. Total number of cell clusters relative to total number of sites containing GFP (single cells + cell clusters) is indicated in parentheses. Approximately four to 14 leaves of each nontransgenic and transgenic tobacco line were bombarded with each plasmid to obtain total numbers indicated.

${ }^{\mathrm{b}}$ Some leaves bombarded with pGFP, p25K:GFP, and pGFP:25K plasmids were maintained for 3 to 5 days post bombardment (dpb). Thus, there are less sites indicated at $3 \mathrm{dpb}$ than at $1 \mathrm{dpb}$ although the proportion of sites remains constant.

${ }^{c}$ Not determined.

d All TGB600 and CP leaves bombarded with pGFP:25K plasmids were maintained for 3 to $5 \mathrm{dpb}$. There is a difference between total number of sites observed between 1 and $3 \mathrm{dpb}$ because a proportion of the sites faded and could not be detected. In these cases no sites were clearly observed at $5 \mathrm{dpb}$. protein accumulation and trafficking on source and sink leaves bombarded with each plasmid. At 1 day post bombardment (dpb), GFP and 25K:GFP proteins were detected in single epidermal cells in nontransgenic tobacco and in TGB100, TGB200, TGB300, TGB600, and CP transgenic tobacco leaves (Table 1; Fig. 2A,B). GFP expression was observed in two adjacent cells in 3 to $5 \%$ of the sites on nontransgenic and transgenic tobacco leaves bombarded with pGFP and p25K:GFP plasmids. Some leaves were maintained for 3 to 5 $\mathrm{dpb}$ and the GFP or $25 \mathrm{~K}$ :GFP proteins still remained in single cells (Table 1). On rare occasions, neighboring cells may have expressed the bombarded genes simultaneously. Similar background levels were reported in related studies in which viral movement protein genes were fused to the GFP gene and delivered to tobacco cells by biolistic bombardment (Itaya et al. 1997; Morozov et al. 1997). GFPs were also reported to move after plasmids containing only the GFP gene were delivered into young leaves (Oparka et al. 1999). It was reported that proteins as large as $50 \mathrm{kDa}$ in size (the GFP is approximately $27 \mathrm{kDa}$ ) can move through plasmodesmata located between immature epidermal cells but not between mature epidermal cells (Oparka et al. 1999). In this study, there were occasions when GFP expression was observed in two adjacent cells but the protein was not observed to move from the initial one or two cells during extended incubations (data not shown).

In contrast, at $1 \mathrm{dpb}, \mathrm{GFP}: 25 \mathrm{~K}$ proteins accumulated in clusters of neighboring cells in nontransgenic tobacco leaves. The GFP:25K proteins were detected in clusters of at least two to three cells in $34 \%$ of the sites analyzed (Fig. 2C; Table $1)$. The number of multiple cell clusters observed on the TGB200 and TGB300 transgenic tobacco bombarded with the pGFP:25K plasmids was slightly higher. Approximately 50\% of the sites observed consisted of multiple cell clusters (Fig. 2C). Protein movement was monitored by measuring the number of fluorescent cells across the diameter of each cell cluster over a period of 5 days. As indicated in Table 2, the fluorescent cell clusters expanded from approximately two to three cells to four to five cells over a 5-day period. To our surprise, GFP:25K fusion protein was restricted to single cells in leaves of TGB600 and CP transgenic tobacco lines (Fig. 2C; Table 1). Only 5 to $6 \%$ of the sites observed at $1 \mathrm{dpb}$ on the TGB600 and CP leaves contained GFP:25K proteins in two adjacent cells. This level is similar to the background level observed on leaves bombarded with pGFP and p25K:GFP plasmids. After $3 \mathrm{dpb}$, GFP:25K still remained in single cells in most cases in TGB600 and CP transgenic tobacco leaves (Table 1). These data indicate that intercellular trafficking of

Table 2. Average number of GFP:25K-containing cells across the diameter of each cell cluster observed during a 5-day period

\begin{tabular}{lccc}
\hline & \multicolumn{3}{c}{ Average cell cluster diameter } \\
\cline { 2 - 4 } Plants & $\mathbf{1 ~ d p b}$ & $\mathbf{3 ~ d p b}$ & $\mathbf{5} \mathbf{~ d p b}$ \\
\hline Nontransgenic & $2.14 \pm 1.65$ & $2.06 \pm 1.57$ & $3.71 \pm 0.39$ \\
TGB200 & $1.97 \pm 1.42$ & $2.11 \pm 1.51$ & $3.60 \pm 0.73$ \\
TGB300 & $2.12 \pm 1.26$ & $2.79 \pm 1.55$ & $4.80 \pm 1.28$ \\
TGB600 & $1.06 \pm 0.24$ & $1.08 \pm 0.57$ & $\mathrm{ND}$ \\
CP & $1.11 \pm 0.43$ & $1.11 \pm 0.47$ & ND \\
\hline
\end{tabular}

a Number of cells across the diameter of each cell cluster was counted; averages and standard deviations are indicated. Total numbers of cell clusters in this table are identical to the numbers listed at 3 days post bombardment $(\mathrm{dpb})$ in Table $1 . \mathrm{ND}=$ not determined. 
GFP:25K fusion proteins was inhibited in the presence of PVX CP or a combination of $12 \mathrm{~K} / 8 \mathrm{~K}$ proteins.

\section{Inhibition of PVX 25K intercellular movement by PVX CP or $12 \mathrm{~K} / 8 \mathrm{~K}$ proteins was specific.}

Inhibition of PVX CP and $12 \mathrm{~K} / 8 \mathrm{~K}$ to PVX $25 \mathrm{~K}$ intercellular trafficking could specifically affect interactions between these PVX proteins or between these PVX and certain host proteins. Alternatively, there could be a general inhibitory mechanism provided by transgenic PVX $\mathrm{CP}$ and $12 \mathrm{~K} / 8 \mathrm{~K}$ proteins that may also block intercellular trafficking of heterologous viral proteins. To distinguish between specific and general inhibition, we bombarded CP and TGB600 transgenic as well as nontransgenic tobacco plants with pRTL2-MP3a:GFP (Itaya et al. 1997). This plasmid carries a DNA construct that expresses GFP fused to the 3a movement protein of Cucumber mosaic virus. 3a:GFP trafficks from cell to cell in tobacco epidermis upon biolistic DNA bombardment (Itaya et al. 1997, 1998). As shown in Table 1, 3a:GFP trafficked from cell to cell in nontransgenic, TGB600, and CP transgenic tobacco leaves. Thus, we concluded that inhibition of PVX 25K intercellular trafficking by PVX CP or the combined $12 \mathrm{~K}$ and $8 \mathrm{~K}$ proteins in the transgenic plants is a specific process.

\section{The 25K:GFP and GFP:25K fusion proteins were localized to different subcellular compartments.}

During our analysis of the trafficking functions of $25 \mathrm{~K}$ :GFP and GFP:25K fusion proteins, we also noticed they had different subcellular localization patterns. In both cases, the fusion proteins were not observed to be associated with the cell wall or plasmodesmata. The 25K:GFP proteins accumulated primarily in cytoplasmic inclusions (Fig. 2B) (Davies et al. 1993). The GFP:25K fusion protein, on the other hand, was dispersed throughout the cytoplasm (Fig. 2C). Since both 25K:GFP and GFP:25K proteins can promote virus cell-to-cell movement (Morozov et al. 1999; this study) we cannot determine whether differences in the subcellular targeting of these two fusion proteins, as viewed by fluorescence microscopy, are significant for protein function. In the transgenic tobacco leaves, the $25 \mathrm{~K}$ :GFP proteins also accumulated in cytoplasmic inclusions, suggesting that the transgenically expressed proteins had no effect on its subcellular targeting. In transgenic leaves expressing the $12 \mathrm{~K}, 8 \mathrm{~K}, \mathrm{CP}$, or the combined $12 \mathrm{~K}$ and $8 \mathrm{~K}$ genes, the GFP:25K proteins appeared soluble throughout the cytoplasm. The fusion proteins also accumulated in nuclei of cells that initially produced the fusion proteins and in cells that imported the proteins (Fig. 2C).

\section{DISCUSSION}

In this paper, we have characterized two properties of the $25 \mathrm{~K}$ protein of PVX. Similar to the $26 \mathrm{~K}$ protein of WCIMV (Lough et al. 1998), the PVX 25K protein can move from cell to cell and this intercellular movement does not require the presence of other PVX-encoded proteins. The second finding reported here is that the potential of the $25 \mathrm{~K}$ protein to move between cells is reduced in the presence of the combined PVX $12 \mathrm{~K}$ and $8 \mathrm{~K}$ proteins or in the presence of the PVX CP.

Lough et al. (1998) proposed a general model describing potexvirus cell-to-cell movement. According to this model, the PVX $25 \mathrm{~K}$ protein forms a complex with the $12 \mathrm{~K}$ and $8 \mathrm{~K}$ proteins that is anchored to the cytoskeleton. Within this complex, the $25 \mathrm{~K}$ protein binds viral RNAs and trafficks to the cell wall. There the $25 \mathrm{~K}$ protein interacts with the viral $\mathrm{CP}$ to transport viral RNA through the plasmodesma. We demonstrated in this study that the PVX $25 \mathrm{~K}$ protein interacts with the $\mathrm{CP}$ and the $12 \mathrm{~K} / 8 \mathrm{~K}$ proteins in plant cells in a manner that inhibits $25 \mathrm{~K}$ protein cell-to-cell trafficking. When purified WCIMV $26 \mathrm{~K}$ protein was injected into transgenic tobacco expressing the $13 \mathrm{~K}$ and $7 \mathrm{~K}$ proteins (homologues of the $12 \mathrm{~K}$ and $8 \mathrm{~K}$ proteins), similar interactions were not observed. Movement of the $26 \mathrm{~K}$ protein was not blocked in those transgenics (Lough et al. 1998). Differences in these observations may be due to differences between the viruses or may be due to the different manners in which the protein was produced.

Based on the WCIMV model, the PVX $12 \mathrm{~K} / 8 \mathrm{~K}$ proteins are predicted to function as membrane anchors for the viral movement complex. The $25 \mathrm{~K}$ protein and $\mathrm{CP}$ would form a complex with the $12 \mathrm{~K}$ and $8 \mathrm{~K}$ anchors and then bind viral RNA to transport it through the plasmodesmata. The data presented in this paper provide evidence of these protein-protein interactions and also suggest that movement of the $25 \mathrm{~K}$ protein through the plasmodesmata is regulated by these proteinprotein interactions. In addition to functioning as membrane anchors, the $12 \mathrm{~K} / 8 \mathrm{~K}$ proteins may also act in combination to temporarily restrict movement of the $25 \mathrm{~K}$ protein into the plasmodesmata. This may promote assembly of the viral RNA within the movement complex, especially with the $25 \mathrm{~K}$ protein. Perhaps binding of viral RNA to the $25 \mathrm{~K}$ protein, or formation of the ribonucleoprotein complex, triggers release of the $25 \mathrm{~K}$ protein from the anchorage site to engage in plasmodesmata trafficking.

PVX movement requires additional participation of the CP. PVX CP accumulates in, but does not gate, plasmodesmata (Oparka et al. 1996). Perhaps the CP blocks sites within the plasmodesmata preventing attachment, and therefore intercellular trafficking, of the $25 \mathrm{~K}$ protein. Alternatively, there may be direct interactions between the cytoplasmic CP and $25 \mathrm{~K}$ protein that restrict $25 \mathrm{~K}$ protein trafficking. At the plasmodesmata, the $25 \mathrm{~K}$ protein may act to push the viral RNA inside while the $\mathrm{CP}$ acts as a conduit for transport of the viral RNA into adjacent cells. Immunolabeling of PVX-infected leaves revealed that the $25 \mathrm{~K}$ protein accumulates primarily in the cytoplasm and has never been seen associated with the interior of the plasmodesmata (Davies et al. 1993). While there is evidence that plasmodesmatal gating and ATPase activity are important functions of the $25 \mathrm{~K}$ protein (Angell et al. 1996; Morozov et al. 1999), there is no evidence yet indicating that cell-to-cell movement of the $25 \mathrm{~K}$ protein itself is required for virus cell-to-cell transport.

The data obtained with these transgenic tobacco may reveal some protein-protein interactions that occur during the progression of the viral infection cycle. It is also possible that autonomous movement of the $25 \mathrm{~K}$ protein may represent an early stage in the infection cycle before there is substantial accumulation of the $12 \mathrm{~K}$ and $8 \mathrm{~K}$ proteins. Expression of the TGB proteins in PVX and related viruses involves two subgenomic RNA species and readthrough translation (Verchot et al. 1998). In principle this could represent a strategy for regulation of the different phases in the infection cycle. The reduced movement capability of the $25 \mathrm{~K}$ protein in the presence of the transgenically expressed, PVX-encoded proteins could 
represent a late stage in the infection cycle when the $12 \mathrm{~K}$ and $8 \mathrm{~K}$ proteins and free $\mathrm{CP}$ accumulate to higher levels. In an earlier study, it was shown that PVX does not replicate in every cell it enters and may continue to move through several cells before replication is initiated (Angell and Baulcombe 1995). Thus, there may be a population of $25 \mathrm{~K}$ proteins that accumulate early in infection that move at the infection front as independent molecules or associated with virions or viral RNA to ensure plasmodesmatal gating for rapid cell-to-cell movement. This could ensure synchronous infection of cells at the infection front as well as ensuring that virus movement is always toward noninfected cells. This may also serve to regulate $25 \mathrm{~K}$ protein-induced plasmodesmatal gating and prevent the spread of defense signaling molecules that may follow the virus through the gated plasmodesmata. Third, the $25 \mathrm{~K}$ protein may be sequestered away from the plasmodesmata when its plasmodesmatal gating activity is no longer required by the virus. This may be necessary to restore normal intercellular communication in cells that are behind the infection front.

The TGB of PVX is a genetic module that is conserved among the hordei-, carla-, furo-, and other potexviruses (Skryabin et al. 1988; Morozov et al. 1989). The first encoded TGB proteins in all cases are similar to the $25 \mathrm{~K}$ protein of PVX in that they share sequence motifs, ATPase activity, and RNA binding activity (Gorbalenya and Koonin 1989; Bleykasten et al. 1996; Donald et al. 1997; Lough et al. 1998; Kalinina et al. 1998; Rouleau et al. 1994). It is likely that these proteins, like the $25 \mathrm{~K}$ protein of PVX, undergo regulated trafficking between cells and that these interactions are required for movement of the virus. A future challenge will be to characterize how these proteins interact with each other, with the viral genome, and with host factors, and to determine the importance of such interactions during virus infection.

\section{MATERIALS AND METHODS}

\section{Bacterial strains and plasmids.}

All plasmids were constructed and used to transform Escherichia coli DH10B (Sambrook et al. 1989). All plasmids were delivered to tobacco leaves by the biolistic bombardment method (see below). The pPVX204 plasmid and its derivatives (Fig. 1A) contain cDNA copies of the PVX genome. The GFP genes were inserted into the PVX genomes under the control of a duplicated sgRNA promoter as described previously (Baulcombe et al. 1995). The pPVX204 plasmid contains the CaMV 35S promoter and nos terminator. The plasmid pPVX204. $\Delta 25 \mathrm{~K}$ has 357 nucleotides deleted from the central region of the $25 \mathrm{~K}$ gene and was prepared previously (Verchot et al. 1998). The pPVX204.GFP25K plasmid was derived from pPVX204.425K. By polymerase chain reaction (PCR), the GFP gene was fused to a wild-type $25 \mathrm{~K}$ gene (see below) and inserted adjacent to the duplicated sgRNA promoter. The GFP:25K fused genes were PCR amplified from pGFP:25K plasmids (see below) with oligonucleotides that introduced a SalI restriction site at the $3^{\prime}$ end of the $25 \mathrm{~K}$ gene. The GFP:25K PCR products and pCX.GFP $\triangle 25 \mathrm{~K}$ were digested with $P m l I$ (a unique restriction site in the GFP gene) and $\mathrm{S} a \mathrm{I}$ and then were ligated together.

Two plasmids containing the PVX $25 \mathrm{~K}$ gene fused to the $5^{\prime}$ end of GFP, and the PVX $25 \mathrm{~K}$ gene fused to the $3^{\prime}$ end of GFP were used for biolistic bombardment of tobacco leaves (Fig.
2A,B, and C). These two plasmids were pUC19 derivatives containing the CaMV 35S promoter and polyadenylation sequences. The p25K:GFP and pGFP:25K translational fusion constructs were prepared with "overlapping" PCRs. The plasmid p25K:GFP contains the GFP gene fused to the 3 ' end of the $25 \mathrm{~K}$ gene and was prepared previously (Malcuit et al. 1999). The pGFP:25K plasmid contains the GFP gene fused to the $5^{\prime}$ end of the $25 \mathrm{~K}$ gene and was prepared by a two-step PCR procedure. First, two oligonucleotides were used to PCR amplify the GFP gene. The $5^{\prime}$ oligonucleotides (YY1) contain an additional Bam $\mathrm{HI}$ site and the $3^{\prime}$ oligonucleotides (YY2) contain 12 addition nucleotides that overlap sequences in the $5^{\prime}$ end of the $25 \mathrm{~K}$ gene. The $25 \mathrm{~K}$ gene was also PCR amplified with $5^{\prime}$ oligonucleotides (YY3) containing an additional 12 nucleotides that overlap sequences in the $3^{\prime}$ end of the GFP gene and 3' oligonucleotides (YY4) containing a SstI site. In the second step, the overlapping PCR products were denatured and annealed to each other. The oligonucleotides YY1 and YY4 were used to amplify the GFP:25K fusion. The final PCR products were digested with BamHI and SstI and gel purified. The p25K:GFP plasmid was also digested with BamHI and SstI, gel purified, and used in ligation reactions with the gel-purified PCR products. The plasmid pGFP was prepared previously (Voinnet and Baulcombe 1997). The plasmid pRTL2-MP3a:GFP was described previously (Itaya et al. 1998).

\section{Plant material.}

Transgenic and nontransgenic Nicotiana tabacum (cv. Petit Havana) plants were used in all experiments. The transgenic tobacco lines TGB100, TGB200, TGB300, TGB600, and CP contain transgenes encoding the PVX $25 \mathrm{~K}, 12 \mathrm{~K}, 8 \mathrm{~K}, 12 \mathrm{~K} / 8 \mathrm{~K}$, or CP genes of PVX, respectively (Fig. 3). These transgenic tobacco plants are able to complement cell-to-cell movement of defective PVX viruses and were described previously (Spillane et al. 1997; Verchot et al. 1998).

\section{Particle bombardment of detached tobacco leaves.}

To identify source and sink tobacco leaves, a mature leaf was excised above the petiole. CF dye (Sigma, St. Louis, MO) was applied to the petiole and its direction of movement was monitored by fluorescence microscopy. The CF dye moves through the phloem from source to sink leaves (Oparka et al. 1994; Roberts et al. 1997). Therefore, accumulation of dye in the upper leaves identified them as sink tissue. Source tissues did not accumulate dye. Microprojectile bombardment of tobacco leaves was conducted with the Biolistic PDS 1000/He System (BioRad, La Jolla, CA) at a pressure of 7,500 kPa with $26 \mathrm{Hg}$ vacuum in the chamber. Ten micrograms of plasmid DNA was combined with $1 \mathrm{mg}$ of $1-\mu \mathrm{m}$ gold particles (BioRad) that was sonicated in $40 \mu \mathrm{l}$ of double-distilled (dd) $\mathrm{H}_{2} \mathrm{O}$. Then, $50 \mu \mathrm{l}$ of $2.5 \mathrm{M} \mathrm{CaCl}_{2}$ and $20 \mu \mathrm{l}$ of $0.1 \mathrm{M}$ spermidine were added and mixed for $15 \mathrm{~min}$ at $4^{\circ} \mathrm{C}$. The DNAcoated gold particles were washed by $70 \%$ ethanol and suspended in $60 \mu \mathrm{l}$ of absolute ethanol. Ten microliters of this mixture was loaded on carrier disk and used for bombardment of detached tobacco leaves (Itaya et al. 1997).

\section{Microscopy.}

GFP was detected with a Nikon Optiphot-2 epifluorescence microscope with a blue excitation filter (420 to $490 \mathrm{~nm}$ ). Fluo- 
rescent images were captured with a Hamamatsu C2400 CCD camera and processed with the Hamamatsu Argus 20 imageprocessing system (Hamamatsu Photonics KK, Hamamatsu, Japan).

\section{ACKNOWLEDGMENTS}

We appreciate the technical support provided by Barbara A. Driskel and Asuka Itaya. We also appreciate the critical reviews of the manuscript provided by Barbara A. Driskel and Hanbing An. Funding was provided by the Oklahoma State Agriculture Experiment Station.

\section{LITERATURE CITED}

Angell, S. M., and Baulcombe, D. C. 1995. Cell-to-cell movement of potato virus $\mathrm{X}$ revealed by microinjection of a viral vector tagged with the $\beta$-glucuronidase gene. Plant J. 7:135-140.

Angell, S. M., Davies, C., and Baulcombe, D. C. 1996. Cell-to-cell movement of potato virus $\mathrm{X}$ is associated with a change in the sizeexclusion limit of plasmodesmata in trichome cells of Nicotiana clevelandii. Virology 216:197-201.

Baulcombe, D. C., Chapman, S., and Santa Cruz, S. 1995. Jellyfish green fluorescent protein as a reporter for virus infections. Plant J. 7: 1045-1053

Bleykasten, C., Gilmer, D., Guilley, H., Richards, K. E., and Jonard, G. 1996. The beet necrotic yellow vein virus 42-kilodalton triple gene block protein binds nucleic acids in vitro. J. Gen. Virol. 77:889-897.

Chapman, S., Hills, G., Watts, J., and Baulcombe, D. C. 1992. Mutational analysis of the coat protein gene of potato virus X: Effects on virion morphology and viral pathogenicity. Virology 191:223-230.

Davies, C., Hills, G., and Baulcombe, D. C. 1993. Sub-cellular localization of the $25-\mathrm{kDa}$ protein encoded in the triple gene block of potato virus X. Virology 197:166-175.

Donald, R. G. K., Lawrence, D. M., and Jackson, A. O. 1997. The barley stripe mosaic virus 58 -kilodalton $\beta$ b protein is a multifunctional RNA binding protein. J. Virol. 71:1538-1546.

Forster, R. L. S., Beck, D. L., Guilford, P. J., Voot, D. M., Van Dolleweerd, C. J., and Andersen, M. T. 1992. The coat protein of white clover mosaic potexvirus has a role in facilitating cell-to-cell transport in plants. Virology 191:480-484.

Gorbalenya, A. E., and Koonin, E. V. 1989. Viral proteins containing the purine NTP-binding sequence pattern. Nucleic Acids Res. 17:84138440.

Huisman, M. J., Linthorst, H. J. M., Bol, J. F., and Cornelissen, B. J. C. 1988. The complete nucleotide sequence of potato virus $\mathrm{X}$ and its homologies at the amino acid level with various plus-stranded RNA viruses. J. Gen. Virol. 69:1789-1798.

Itaya, A., Hickman, H., Bao, Y., Nelson, R., and Ding, B. 1997. Cell-tocell trafficking of cucumber mosaic virus movement protein: Green fluorescent protein fusion produced by biolistic gene bombardment in tobacco. Plant J. 12:1223-1230.

Itaya, A., Woo, Y.-M., Masuta, C., Bao, Y., Nelson, R. S., and Ding, B. 1998. Developmental regulation of intercellular protein trafficking through plasmodesmata in tobacco leaf epidermis. Plant Physiol. 118: 373-385.

Kalinina, N. O., Samuilova, O. V., Fedorkin, O. N., Zelenina, D. A., and Morozov, S. Y. 1998. Biochemical characterization and subcellular localization of a $25 \mathrm{~K}$ transport protein of potato virus X. Mol. Biol.
32:569-573.

Koonin, E. V., and Dolja, V. V. 1993. Evolution and taxonomy of positive-strand RNA viruses: Implications of comparative analysis of amino acid sequences. Crit. Rev. Biochem. Mol. Biol. 28:375-430.

Lough, T. J., Shash, K., Xoconostle-Cazares, B., Hofstra, K. R., Beck, D. L., Balmori, E., Forster, R. L. S., and Lucas, W. J. 1998. Molecular dissection of the mechanism by which potexvirus triple gene block proteins mediate cell-to-cell transport of infectious RNA. Mol. PlantMicrobe Interact. 11:801-814.

Malcuit, I., Marano, M. R., Kavanagh, T. A., De Jong, W., Forsyth, A., and Baulcombe, D. C. 1999. The 25-kDa movement protein of PVX elicits $N b$-mediated hypersensitive cell death in potato. Mol. PlantMicrobe Interact. 12:536-543.

Morozov, S. Y., Dolja, V. V., and Atabekov, J. G. 1989. Probable reassortment of genomic elements among elongated RNA-containing plant viruses. J. Mol. Evol. 29:52-62.

Morozov, S. Y., Fedorkin, O. N., Juttner, G., Schiemann, J., Baulcombe, D. C., and Atabekov, J. G. 1997. Complementation of a potato virus X mutant mediated by bombardment of plant tissues with cloned viral movement protein genes. J. Gen. Virol. 78:2077-2083.

Morozov, S. Y., Solovyev, A. G., Kalinina, N. O., Fedorkin, O. N., Samuilova, O. V., Schiemann, J., and Atabekov, J. G. 1999. Evidence for two nonoverlapping functional domains in the potato virus X $25 \mathrm{~K}$ movement protein. Virology 260:55-63.

Oparka, K. J., Duckett, C. M., Prior, D. A. M., and Fisher, D. B. 1994 Real-time imaging of phloem unloading in the root tip of Arabidopsis. Plant J. 6:759-766.

Oparka, K. J., Roberts, A. G., Poevink, P., Santa Cruz, S., Roberts, I., Pradel, K. S., Imlau, A., Kotlizky, G., Sauer, N., and Epel, B. 1999. Simple, but not branched, plasmodesmata allow the nonspecific trafficking of proteins in developing tobacco leaves. Cell 97:743-754.

Oparka, K. J., Roberts, A. G., Roberts, I. M., Prior, D. A. M., and Santa Cruz, S. 1996. Viral coat protein is targeted to but does not gate plasmodesmata during cell-to-cell movement of potato virus X. Plant J. 10:805-813.

Roberts, A. G., Santa Cruz, S., Roberts, I. M., Prior, D. A. M., Turgeon, R., and Oparka, K. J. 1997. Phloem unloading in sink leaves of Nicotiana benthamiana: Comparison of a fluorescent solute with a fluorescent virus. Plant Cell 9:1381-1396.

Rouleau, M., Smith, R. J., Bancroft, J. B., and Mackie, G. A. 1994. Purification, properties, and subcellular localization of foxtail mosaic potexvirus 26-kDa protein. Virology 204:254-265.

Sambrook, J., Fritsch, E. F., and Maniatis, T. A. 1989. Molecular Cloning: A Laboratory Manual. 2nd ed. Cold Spring Harbor Laboratory, Cold Spring Harbor, NY.

Santa Cruz, S., Roberts, A. G., Prior, D. A. M., Chapman, S., and Oparka, K. J. 1998. Cell-to-cell and phloem-mediated transport of potato virus X: The role of virions. Plant Cell 10:495-510.

Skryabin, K. G., Morozov, S.Y., Kraev, A. S., Rozanov, M. N., Chernov, B. K., Lukasheva, L. I., and Atabekov, J. G. 1988. Conserved and variable elements in RNA genomes of potexviruses. FEBS Lett. 240: 33-40.

Spillane, C., Verchot, J., Kavanagh, T. A., and Baulcombe, D. C. 1997. Concurrent suppression of virus replication and rescue of movementdefective virus in transgenic plants expressing the coat protein of potato virus X. Virology 236:76-84.

Verchot, J., Angell, S. M., and Baulcombe, D. C. 1998. In Vivo translation of the triple gene block of potato virus $\mathrm{X}(\mathrm{PVX})$ requires two mRNAs. J. Virol. 72:8316-8320.

Voinnet, O., and Baulcombe, D. C. 1997. Systemic signalling in gene silencing. Nature 389:553. 